\title{
Microwave sintering of titanium
}

\section{Shudong Luo, ${ }^{1, a}$, C.J. Bettles ${ }^{2, b}$, M. Yan ${ }^{1, c}$, G. B. Schaffer ${ }^{1, d}$, Ma Qian $^{1, e^{*}}$}

${ }^{1}$ The University of Queensland, School of Mechanical and Ming Engineering, ARC Centre of Excellence for Design in Light Metals, Brisbane QLD 4072, Australia

\author{
${ }^{2}$ Monash University, ARC Centre of Excellence for Design in Light Metals, \\ Clayton, Victoria 3800, Australia \\ as.luo1@uq.edu.au, bcolleen.bettles@eng.monash.edu.au, cm.yan2@uq.edu.au, \\ g.schaffer@uq.edu.au, ${ }^{e}$ ma.qian@uq.edu.au (corresponding author)
}

Keywords: Microwave sintering; microwave heating; titanium

\begin{abstract}
Effective sintering of titanium requires the use of a high sintering temperature $\left(\geq 1200^{\circ} \mathrm{C}\right)$, preferably in high vacuum $\left(<10^{-2} \mathrm{~Pa}\right)$. This confines the heating and cooling rates to $\sim 4{ }^{\circ} \mathrm{C} / \mathrm{min}$ because of the limited thermal shock resistance of ceramic tube furnaces. Consequently, it leads to lengthy sintering cycles (10-12 hr). This work presents an assessment of microwave (MW) sintering of titanium. Titanium powders in the size ranges of $<20 \mu \mathrm{m}, 45-63 \mu \mathrm{m}$, and 100-150 $\mu \mathrm{m}$ were used to make green samples with compaction pressures ranging from 200-800 $\mathrm{MPa}$. Sintering was carried out at $1200^{\circ} \mathrm{C}$ for $2 \mathrm{hr}$ in a $3 \mathrm{~kW}$ MW furnace with a $2.45 \mathrm{GHz}$ multimode cavity under a vacuum of $2-6 \times 10^{-3} \mathrm{~Pa}$. The characteristics of MW heating of green titanium samples in vacuum are described in terms of the heating rate, vacuum fluctuations, and sparking discharge. The actual MW heating rate achieved from $350{ }^{\circ} \mathrm{C}$ to $1200{ }^{\circ} \mathrm{C}$ was $34{ }^{\circ} \mathrm{C} / \mathrm{min}$. The attendant densities are comparable to those attained by conventional vacuum sintering. Cross-sectional examinations revealed a fairly uniform pore distribution in MW-sintered samples made from either the coarse or fine titanium powder.
\end{abstract}

\section{Introduction}

The applications of titanium and its alloys are manifold, but are largely confined to niche markets that can support the cost of the components. The cost penalties occur at every stage of processing, from the production of the initial ingot feedstock, through various intermediate shaping stages and final treatments for development of the optimum properties. It has been recognised that powder metallurgy $(\mathrm{P} / \mathrm{M})$ techniques can be applied to Ti for near net shape manufacturing. This is particularly attractive to the aerospace area where the buy-to-fly ratio can be prohibitive. The target set by Lockheed Martin for the F35 Program is to reduce the buy-to-fly ratio to 5:1 [1], from the more usual 8:1 [2]. However, Ti $\mathrm{P} / \mathrm{M}$ is not without economic hurdles. The primary hurdle is the commercial supply of low cost, high purity titanium powder. Figure 1 gives a cost comparison. High purity Ti powder (for example $\mathrm{HDH} \mathrm{Ti}$, rather than titanium sponge fines which may contain high chlorine levels) is substantially more expensive than $\mathrm{Cu}, \mathrm{Fe}$ and $\mathrm{Al}$ powders. Concerted attempts are being made to produce low cost, high purity $\mathrm{Ti}$ powder, and if any of these are successful then the opportunities for Ti P/M may increase dramatically.

The consolidation step resulting in a green compact can be carried out at room temperature using standard presses in closed steel dies and does not contribute much to the overall cost. The sintering stage, however, has a number of challenges; most are associated with the high affinity of Ti for oxygen and nitrogen. These contaminants can change the microstructural makeup of the component, favouring the stability of $\alpha-\mathrm{Ti}$ and causing increases in strength and reductions in ductility. To minimise the pick-up of oxygen and nitrogen, high-vacuum sintering is preferred, although a high purity argon or helium atmosphere can be used as well. However, the heating and cooling rates are usually slow for high-vacuum sintering due to the limited thermal shock resistance of the ceramic tube furnaces. If shorter sintering cycles are realised, the productivity will be increased and less energy will be consumed accordingly. In addition, limits on atmosphere (vacuum or argon; helium is comparatively expensive) purity may be partly relaxed depending on the magnitude of any reduction 
in the sintering cycle that may be realised. Novel rapid sintering processes are thus particularly attractive. Microwave (MW) sintering is one such possible option, where some powdered metals are known to couple well with microwaves and heat up effectively, with heating rates up to $\sim 100{ }^{\circ} \mathrm{C}$ $\min ^{-1}[3,4]$. However, there have been few reports on the sintering of titanium by MW radiation. Two studies $[5,6]$ used MW sintering in argon to produce gradient surface porosity in titanium for dental applications and another [7] sintered titanium in argon at $1600 \mathrm{~K}$ and achieved a maximum density of $91.1 \%$. None has focused on full sintering of titanium by MW radiation. Recent attempts to use the MW radiation to heat titanium powders in air showed that titanium powders coupled very weakly with MW radiation [8]. This work investigates the MW sintering characteristics of titanium and assesses its potential as a cost-effective processing route against conventional vacuum sintering.

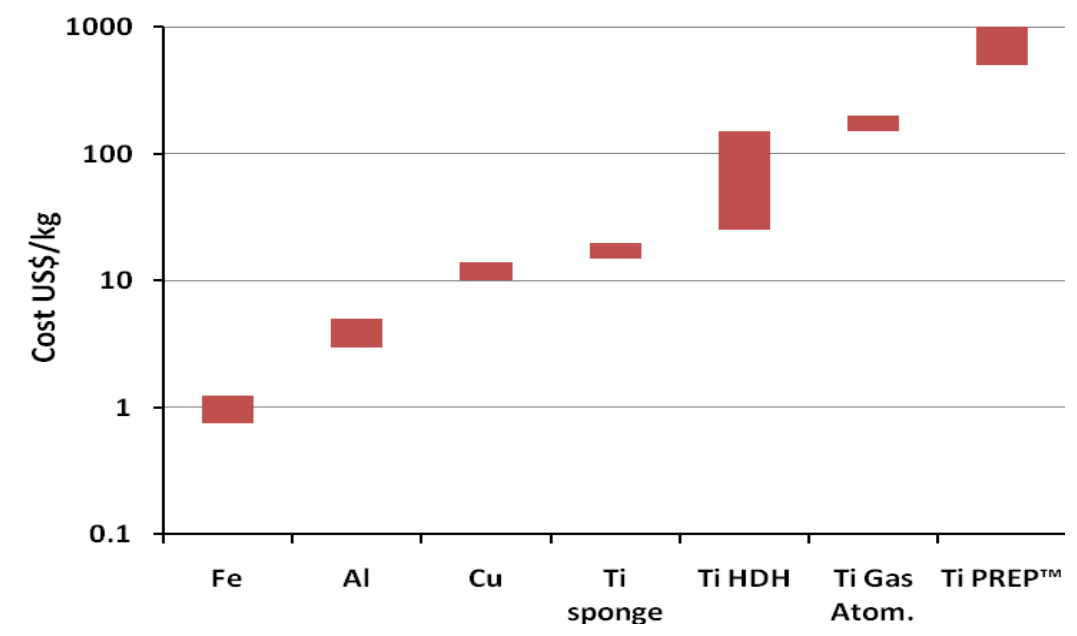

Fig. 1 Cost comparison of metal powders. Ti powder costs are from [9, 10].

\section{Experimental procedure}

Three types of Ti powders, supplied by Sumitomo Titanium Incorporation (SUMI-Ti, 99.5\% purity), CERAC Incorporated (CERAC-Ti, 99.5\% purity) and Atlantic Equipment Engineers (AEE-Ti, 99.7\% purity), were used. The SUMI-Ti and CERAC-Ti powders have a similar particle size, -100 mesh, from which the powder fractions $45-63 \mu \mathrm{m}$ and 100-150 $\mu \mathrm{m}$ were sieved. The AEE-Ti has a particle size $<20 \mu \mathrm{m}$. Cylinder compacts (diameter: $10 \mathrm{~mm}$; height: $10 \mathrm{~mm}$ ) were made by uniaxially pressing respective powders in a floating cylindrical die at 200-800 MPa. Acrawax was applied lightly to the die wall. De-waxing was carried out in acetone.

A $3 \mathrm{~kW}$ high-vacuum MW furnace with a $2.45 \mathrm{GHz}$ multimode cavity (HAMilab-HV3, SYNOTHERM, China) was employed. Figure 2 illustrates the sintering setup. Green samples were placed in an insulation package of alumina $\left(\mathrm{Al}_{2} \mathrm{O}_{3}\right)$ fibre block and surrounded by silicon carbide ( $\mathrm{SiC}$ ) susceptors. The package was positioned at the centre of the cavity and rotated clockwise at 4-5 rpm. Temperature was measured using an infrared pyrometer (Raytek MA2SC, 350-2000 ${ }^{\circ} \mathrm{C}$, US) and controlled by manually adjusting the input MW power. The de-waxed compacts were sintered at $1200{ }^{\circ} \mathrm{C}$ for $120 \mathrm{~min}$. For comparison, similar compacts were sintered in vacuum $\left(>10^{-2} \mathrm{~Pa}\right)$ conventionally.

The green density of each compact was calculated from its mass and dimensions. Sintered density was measured using the Archimedes method according to ASTM Standard B328 (MPIF Standard 42). The pore-filling liquid used was Mobil DTE25 oil with a specific gravity of 0.87 and the test liquid was a hydro-fluoro-polyether heat transfer fluid with a specific gravity of 1.68 (H-Galden ZT-180 supplied by Solvay-Solexis). Cross-sections were polished using colloidal silica with 3 vol.\% hydrogen peroxide and examined unetched or etched (Kroll's etchant) using an optical microscope and a scanning electron microscope (SEM, JOEL JSM 6460LA model). X-ray diffraction (XRD, $\mathrm{D} / \mathrm{max}$ III, $\mathrm{Cu} \mathrm{K}_{\alpha}$ target, operated at $40 \mathrm{kV}$ and $60 \mathrm{~mA}$ ) was used to analyse the sintered samples. 


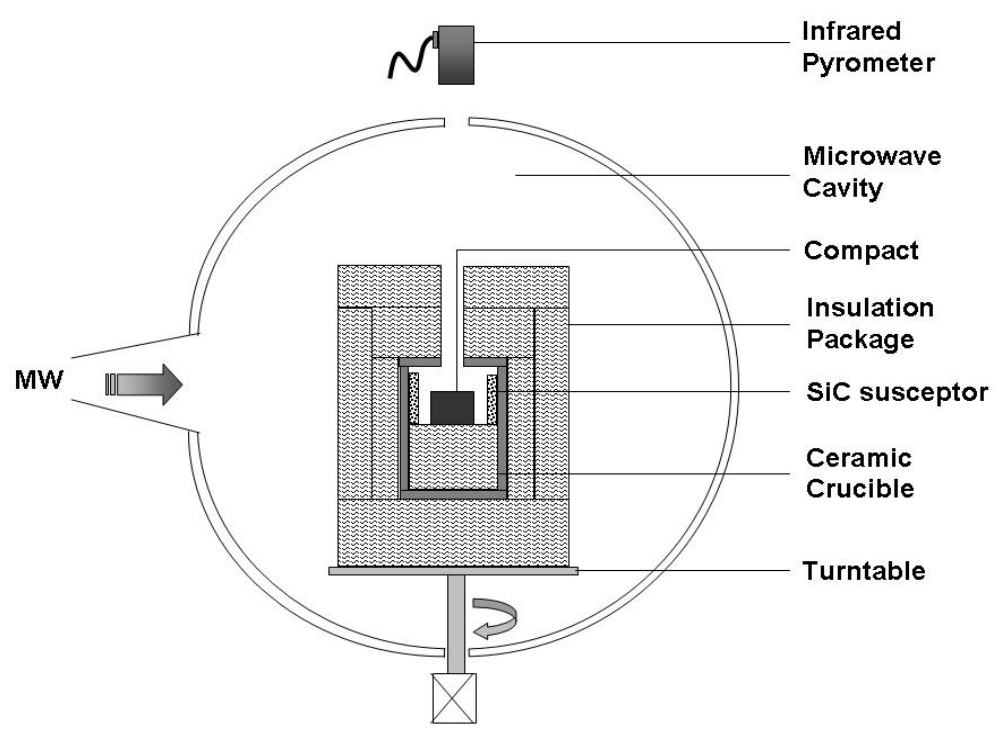

Fig. 2 Schematic diagram of the microwave sintering configuration.

\section{Results and discussion}

\section{Microwave heating in high vacuum}

Figure 3 shows the temperature profile, input power variations and vacuum changes recorded during MW heating and isothermal sintering of four titanium samples. It took about 55 min to reach $350{ }^{\circ} \mathrm{C}$, the minimum temperature measurable by the infrared pyrometer. The heating rate in this initial stage was mainly determined by the input MW power, although sample loading, the insulation capacity and the performance of the susceptors also play a role. It can be significantly increased. However, it was found that the vacuum condition varied widely in the initial stage due to the vaporization of residual wax and the escape of hydrogen and moisture from the titanium powders. It dropped to about $2 \times 10^{-2}$ $\mathrm{Pa}$ on the initial input of MW power, fluctuated with time and recovered to about $9 \times 10^{-3} \mathrm{~Pa}$ when the temperature reached $350{ }^{\circ} \mathrm{C}$. Because of the vacuum conditions, the input power was intentionally controlled for slow heating in the initial stage. After that, the vacuum improved consistently and was suitable for rapid heating without obvious oxidation. As a result, samples were heated from $350{ }^{\circ} \mathrm{C}$ to $1200{ }^{\circ} \mathrm{C}$, the sintering temperature, in $25 \mathrm{~min}$, against $\sim 212 \mathrm{~min}$ by conventional vacuum sintering (heating rate: $4{ }^{\circ} \mathrm{C} / \mathrm{min}$ ). The MW generator was turned off after $120 \mathrm{~min}$ sintering at temperature and the samples cooled in the furnace accordingly. The overall MW energy used for each sintering cycle is $\sim 1.4 \mathrm{kWh}$. Another phenomenon observed during MW heating is the sparking discharge that occurred between the susceptors or the susceptors and titanium samples. Sparking discharge is a universal phenomenon of MW heating under high vacuum. It occurred predominantly below $800{ }^{\circ} \mathrm{C}$ in our sintering trials (see Figure 3). Technically, slow heating and use of low input MW power help to depress the discharge. Nevertheless, sparking below $800{ }^{\circ} \mathrm{C}$ exerts little impact on the final microstructure. The major risk is that severe sparking disrupts the heating process.

\section{Densification}

All MW-sintered samples show uniform shrinkage. Relative densities as high as $96.30 \%$ were attained in samples made from the AEE-Ti powder $(<20 \mu \mathrm{m})$. Figure 4 compares the sintered densities. Using fine starting powders or higher compaction pressures is beneficial to densification by MW sintering, which is similar to conventional sintering processes [11]. The results show that MW sintering of titanium in high vacuum is comparable, to conventional vacuum sintering. In general, sintered densities around 95\% will be adequate for non-fatigue applications while lower sintered densities around $92 \%$ can be used as feedstock preforms for subsequent hot working. MW sintering is capable of serving both purposes. 


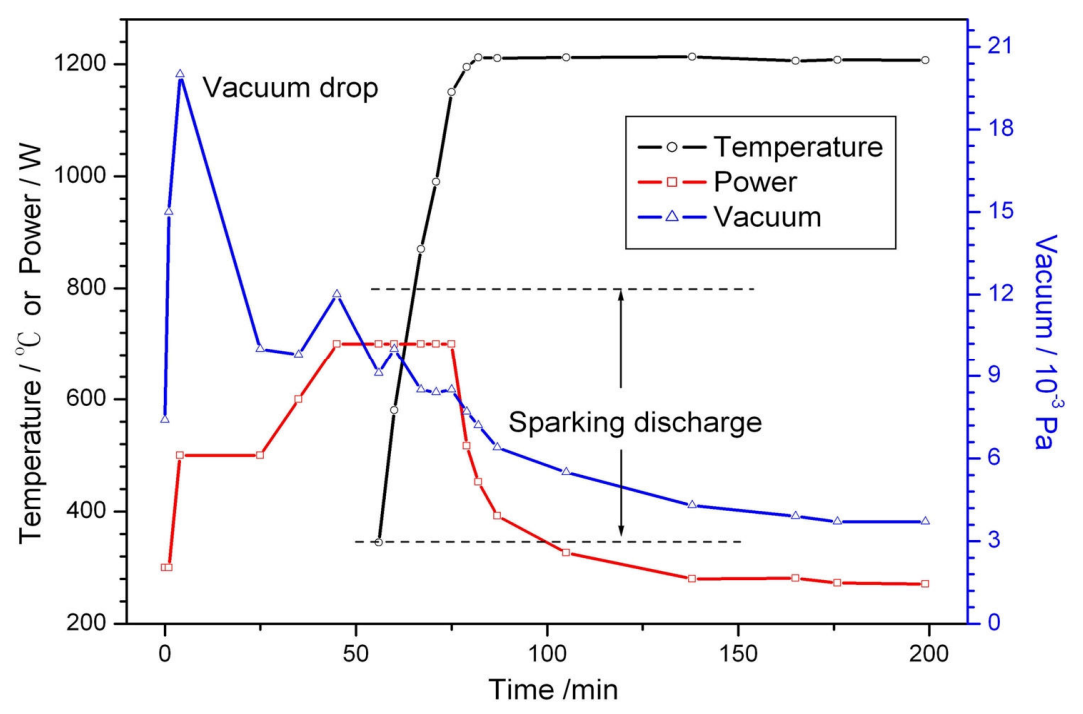

Fig. 3 Temperature, input microwave power, and vacuum profiles during microwave sintering.

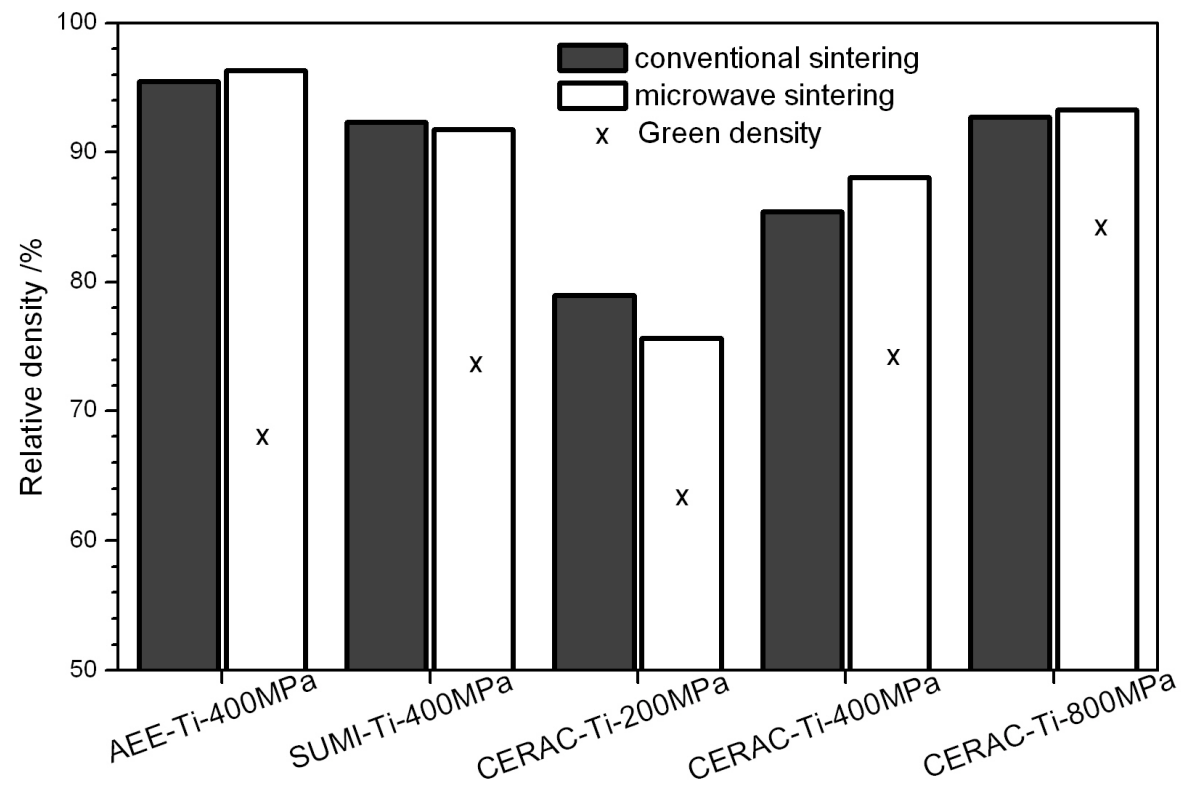

Fig. 4 Densification from microwave and conventional sintering. AEE-Ti: $<20 \mu \mathrm{m}$; SUMI-Ti: $45-63$ $\mu \mathrm{m}$; CERAC-Ti: 100-150 $\mu \mathrm{m}$.

\section{Microstructures}

Figures 5 and 6 show cross-sectional views of both MW-sintered and conventionally sintered samples made from CERAC-Ti and SUMI-Ti. The images were captured along the axial direction of each sintered sample measuring about $10 \mathrm{~mm}$ in distance. There is no visible difference in the pore distribution and pore sizes between the MW-sintered and conventionally sintered samples made from the CERAC-Ti powder (Figure 5). However, there is a noticeable difference between samples made from the SUMI-Ti powder (Figure 6). Compared to the uniform pore distribution in the MW-sintered sample, a number of large pores are observed at the centre of the conventionally sintered sample (Figure 6 a). Also, the pore population at the centre is obviously higher than in the edge.

For samples made from the relatively coarse CERAC-Ti powder (Figure 4), the attendant relative densities are lower than the $92 \%$ threshold $(88.08 \%$ for MW-sintered and $85.44 \%$ for conventionally sintered) [11], whilst for those made from the finer SUMI-Ti powder, the attendant relative densities are around $92 \%$ (91.77\% for $\mathrm{MW}$-sintered and $92.30 \%$ for conventionally sintered). MW sintering is similarly affected by the powder size. However, it is encouraging to note that MW sintering resulted 
in a fairly uniform pore distribution in samples made from either the coarse CERAC-Ti powder (Fig. $5 \mathrm{~b}$ ) or the fine SUMI-Ti powder (Fig. 6 b). This agrees with the general knowledge that MW heating produces a relatively uniform temperature distribution in small samples [12].

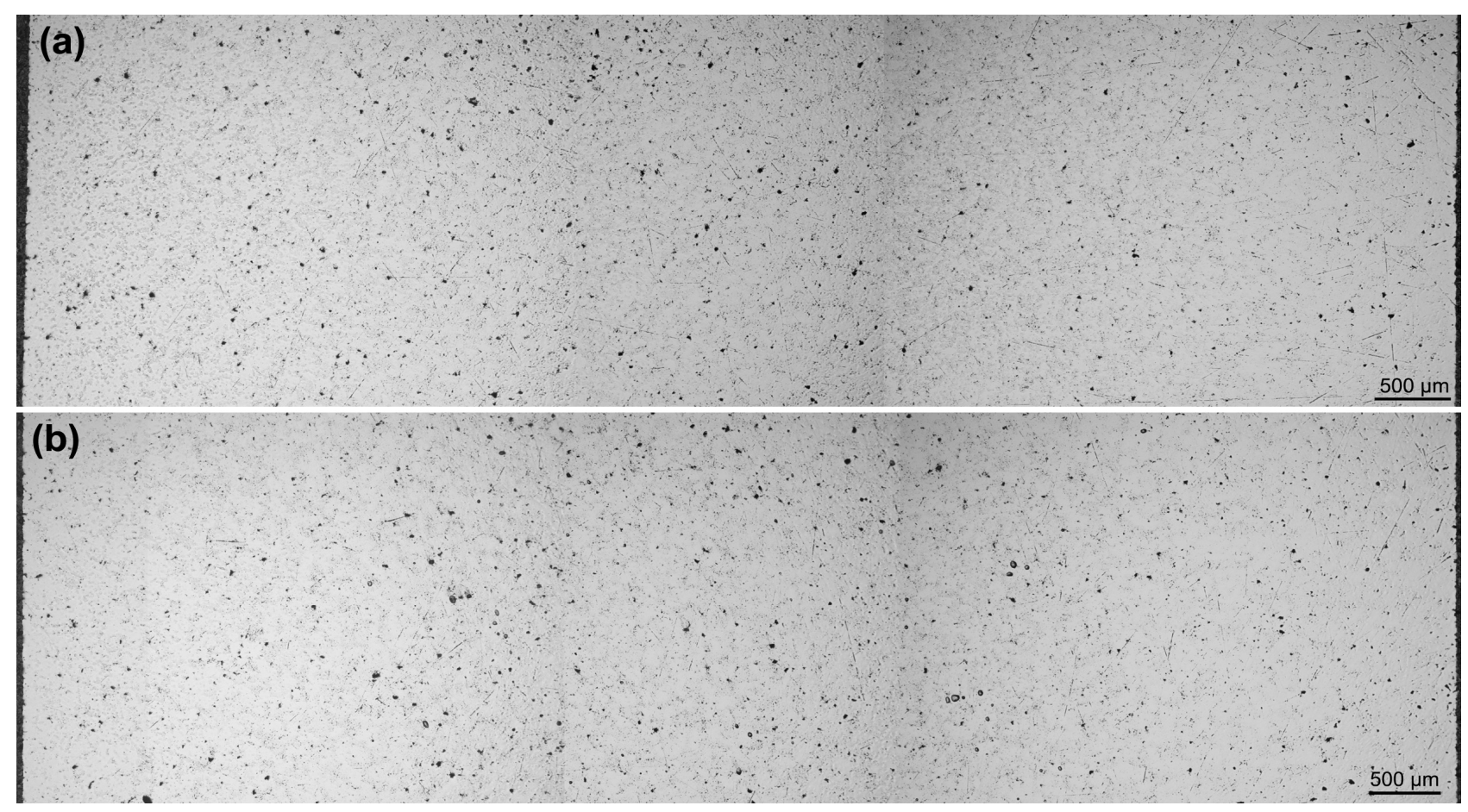

Fig. 5 Pore distribution in (a) conventionally sintered and (b) microwave sintered CERAC-Ti samples Powder size: $100-150 \mu \mathrm{m}$; compaction pressure: $400 \mathrm{MPa}$; sintering practice: $1200{ }^{\circ} \mathrm{C} \times 2 \mathrm{hr}$.

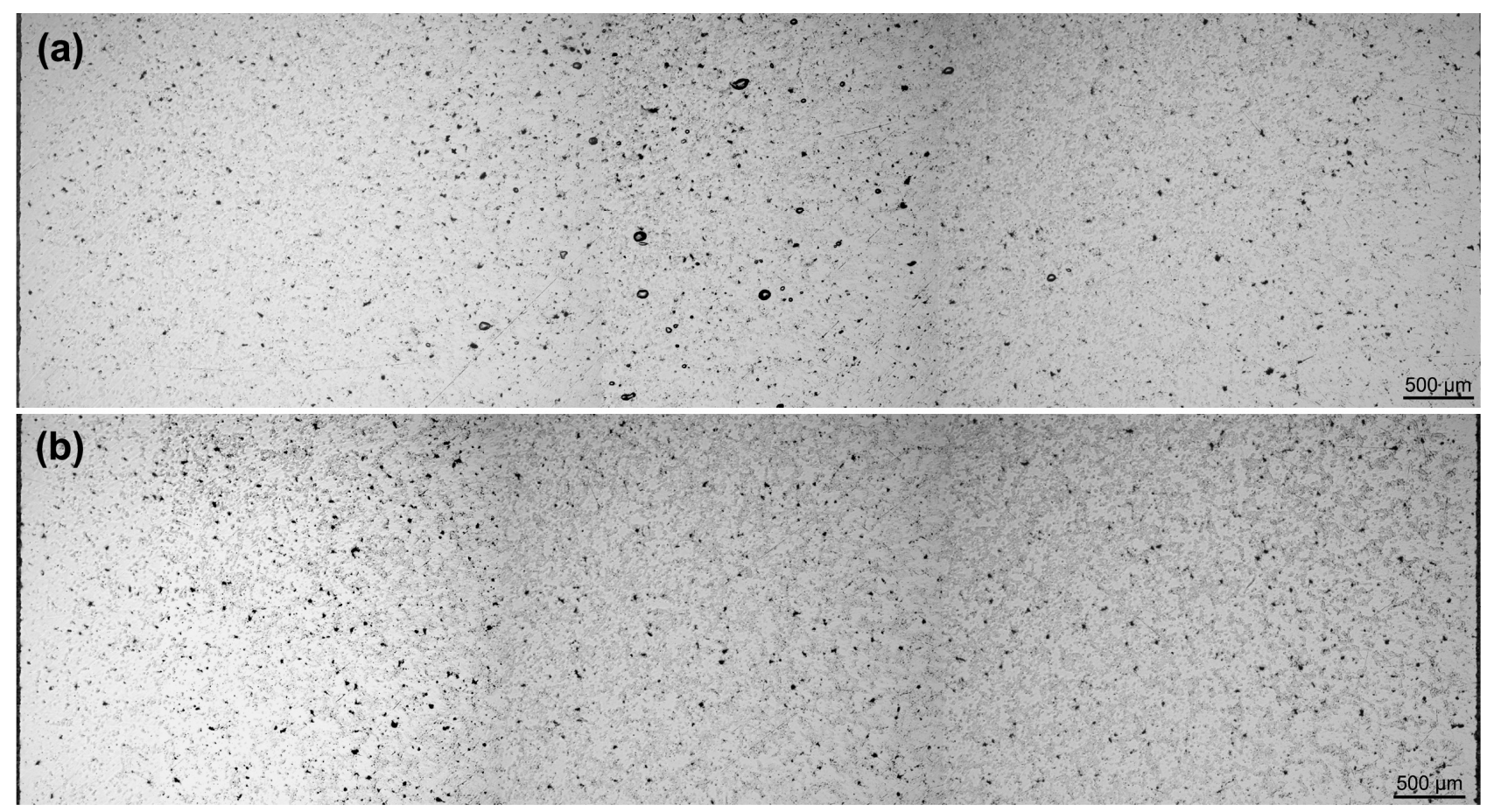

Fig.6 Pore distribution in (a) conventionally sintered and (b) microwave sintered SUMI-Ti samples. Powder size: 45-63 $\mu \mathrm{m}$; compaction pressure: $400 \mathrm{MPa}$; sintering practice: $1200{ }^{\circ} \mathrm{C} \times 2 \mathrm{hr}$.

As expected, XRD analyses of MW-sintered samples revealed $\alpha$-Ti only. Kroll's etchant was applied to the polished surfaces to reveal the microstructure. Figure 7 compares the sintered microstructures 
of samples made from the CERAC-Ti powder. Straight grain boundaries are observed in both conventionally sintered and MW-sintered samples, indicative of the formation of polygonal $\alpha-\mathrm{Ti}$ grains and significant sintering. Pores are observed both within the grains and along grain boundaries. However, in the MW-sintered samples, many pores show nearly spherical or round-edged morphologies. This is consistent with observations made previously on the MW sintering of other metal systems [13]. Such pore morphologies are believed to have a beneficial effect on the ductility and toughness of the sintered material [13]. However, quantitative measurements of the average grain size over 1000 grains from each sample confirmed the observation that the average grain size (80.4 $\mu \mathrm{m})$ in the MW-sintered sample is larger than that $(66.9 \mu \mathrm{m})$ in the conventionally sintered sample. Further work is needed to understand the observation.

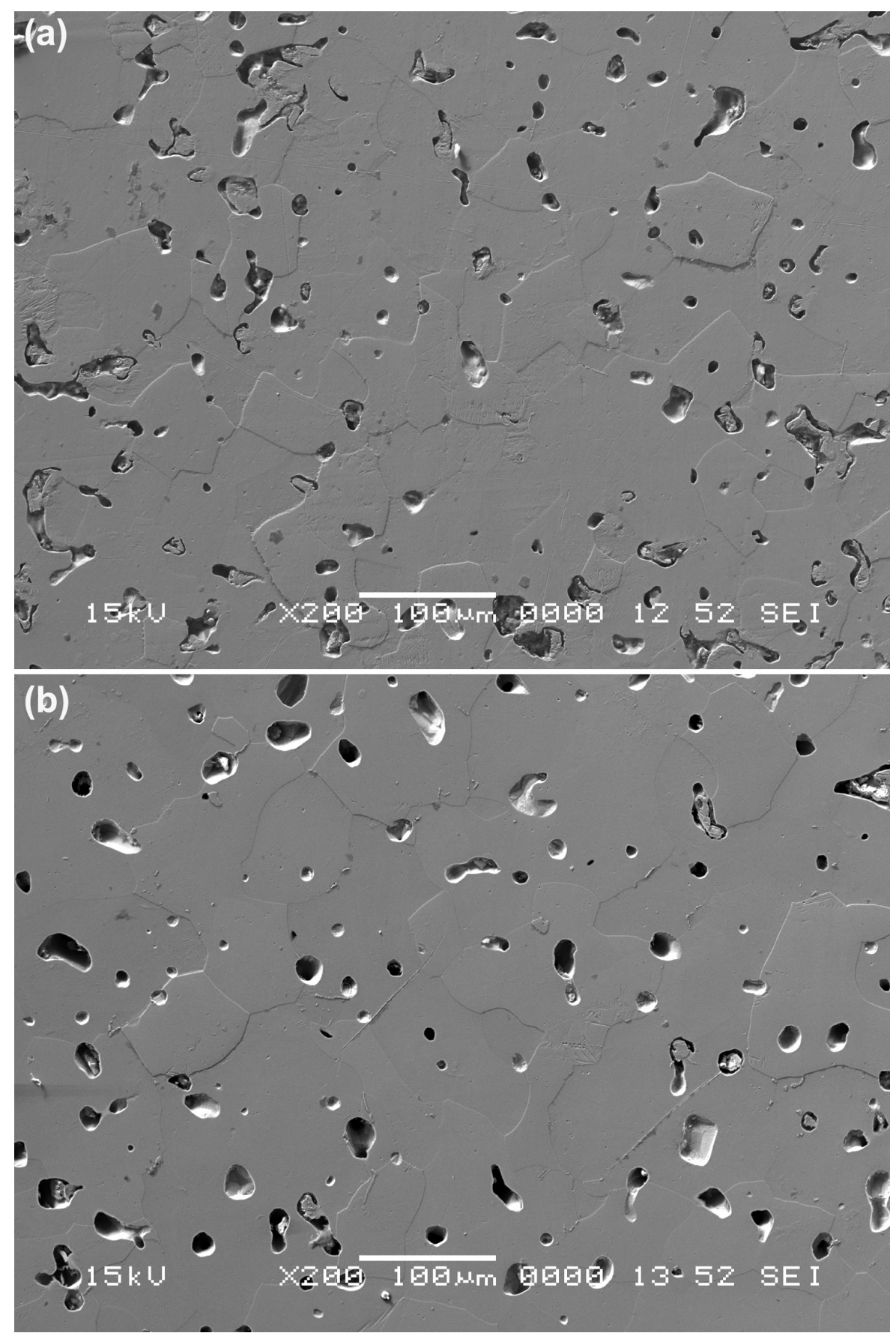

Fig. 7 SEM micrographs of sintered samples made from the CERAC-Ti powder $(100-150 \mu \mathrm{m})$ : (a) conventionally sintered (85.44\%); average grain size: $66.9 \mu \mathrm{m}$ and (b) microwave sintered (88.08\%); average grain size: $80.4 \mu \mathrm{m}$. Compaction pressure: $400 \mathrm{MPa}$; sintering practice: $1200{ }^{\circ} \mathrm{C} \times 2 \mathrm{hr}$. 


\section{Summary}

The use of microwave energy to sinter green titanium compacts in high vacuum has been demonstrated using three different types of titanium powder. A heating rate of $34^{\circ} \mathrm{C} / \mathrm{min}$ was comfortably achieved from $350{ }^{\circ} \mathrm{C}$ to $1200{ }^{\circ} \mathrm{C}$ compared to $\sim 4{ }^{\circ} \mathrm{C} / \mathrm{min}$ used in conventional vacuum heating in ceramic tube sintering furnaces. The sintered densities by microwave radiation are comparable to those attained by conventional vacuum sintering. Microwave sintering resulted in a fairly uniform pore distribution. However, some processing issues were encountered including wide fluctuations in vacuum at low temperatures $\left(<350^{\circ} \mathrm{C}\right)$ and sparking discharges below $800{ }^{\circ} \mathrm{C}$. These processing issues may imply that a slow heating rate needs to be used in the initial stage of microwave radiation. Nevertheless, the fast heating rate achieved at temperatures above $350{ }^{\circ} \mathrm{C}$ implies that microwave sintering has potential as a cost-effective processing route for titanium powder metallurgy.

Acknowledgements: This work was supported by the Australian Research Council (ARC) Centre of Excellence for Design in Light Metals.

\section{References}

[1] J.E. Barnes, W. Peter and C.A. Blue: Mater. Sci. Forum Vol. 618-619 (2009), p.165

[2] DuPont: Metal Powder Report Vol. 61 (2006), p. 4

[3] K. Saitou: Scripta Mater. Vol. 54 (2006), p. 875

[4] C.S. Zhou, J.H. Yi, S.D. Luo, Y.D. Peng, L.Y. Li and G. Chen: J. Alloy Compd. Vol. 482 (2009), p. L6

[5] M.G. Kutty, S. Bhaduri, J.R. Jokisaari and S.B. Bhaduri: Cera. Eng. Sci. Proc. Vol. 22 (2001), p. 587

[6] M.G. Kutty, S. Bhaduri and S.B. Bhaduri: J. Mater. Sci.: Mater. Med. Vol. 15 (2004), p. 145

[7] T. Hayashi, in: Reports of Research Institute of Industrial Products Technology, Gifu (2005), No.6, p. 129

[8] V. D. Buchelnikov, D. V. Louzguine-Luzgin, G. Xie, S. Li, N. Yoshikawa, M. Sato, A. P. Anzulevich, I. V. Bychkov, and A. Inoue, J. Appl. Phys. Vol. 104, (2008), 113505.

[9] L. Hogan, E. Mcginn and R. Kendall, in: Research and development in titanium: implications for a titanium metal industry in Australia, Research Report (2008), Information on http://www.abare.gov.au (08.2)

[10] Information on http://www.titaniuminfogroup.com Data sheet 16 [visited 2 December 2009]

[11] R.M. German: Powder Metallurgy Science (Metal Powder Industries Federation, US 1994).

[12] A. Chatterjee, T. Basak and K.G. Ayappa: AIChe Journal Vol. 44 (1998), p. 2302

[13] R. Roy, D. Agrawal, J. Cheng, and S. Gedevanishvili, Nature Vol. 399 (1999), p. 668 